\title{
Volumetric, Hemodynamic, and Excretory Characteristics of the Liver in Acromegaly*
}

\author{
Rudolf Preisig, $\dagger$ Thomas $Q$. Morris, Joyce C. Shaver, $\ddagger$ and \\ Nicholas P. Christy $\S$ \\ (From the Department of Medicine, Columbia University College of Physicians E Surgeons, \\ and the Presbyterian Hospital, Neze York, N.Y.)
}

Comprehensive autopsy studies $(1,2)$ have disclosed that enlargement of the viscera, including the heart, lungs, kidneys, pancreas, adrenals, and particularly the liver, is a prominent and consistent feature of acromegaly. The detailed structural changes responsible for visceromegaly in patients with this disease are poorly understood. Studies of the functional alterations of the hypertrophied organs are few and have been focused almost exclusively on the kidneys. Increased renal plasma flow, glomerular filtration rate, and proximal tubular functions have been demonstrated (3-5). It seemed reasonable, therefore, to expect that blood flow and excretory function of the liver might also be augmented.

Precise appraisal of liver size by clinical examination alone is difficult; furthermore, evaluation of hepatic hyperfunction cannot be made with routine liver function tests. The introduction of methods for measurement of splanchnic blood flow and volume $(6,7)$ and for estimation of sulfobromophthalein (BSP) kinetics $(8,9)$ has made quantitative determination of hepatic function possible. Correlation of function with hepatic size is feasible owing to the development of techniques for quantification of "liver volume" (10).

The results of such studies, carried out in $11 \mathrm{pa-}$

* Submitted for publication January 12, 1966; accepted May 24, 1966.

Supported by grants from the John A. Hartford Foundation and from the National Institutes of Health (AM-04035, AM-07970, and TI AM-5397).

Presented in part at the Fifty-seventh Annual Meeting of the American Society for Clinical Investigation, Atlantic City, N. J., May 2, 1965.

† Present address: Dept. of Clinical Pharmacology, University of Berne, Switzerland.

$\ddagger$ Present address: Dept. of Medicine, Roosevelt Hospital, New York, N. Y.

§ Address requests for reprints to Dr. Nicholas $P$. Christy, Dept. of Medicine, Roosevelt Hospital, New York, N. Y. tients with acromegaly, are reported in this paper. The data confirm the presence of hepatomegaly, demonstrate a marked increase in hepatic excretory capacity for $\mathrm{BSP}$, and suggest a relative reduction in hepatic parenchymal perfusion.

\section{Methods}

The subjects of this study were 11 patients ( 6 men, 5 women) with classical features of acromegaly. Their ages ranged from 41 to 66 years. All patients were ambulatory, and all were admitted to the Presbyterian Hospital for the sole purpose of this study. All patients were studied on an air-cushioned fluoroscopy table after an overnight fast.

\section{Procedures}

Estimation of hepatic blood flow $(E H B F)$. Catheterization of a right hepatic vein was performed under fluoroscopic control, with a number eight Cournand or Lehman catheter. An indwelling polyethylene catheter ${ }^{1}$ placed in a vein of the opposite arm served as infusion site. Arterial blood samples were obtained through a Cournand needle, which had been inserted percutaneously into a brachial artery.

To determine EHBF with the dye dilution and extraction technique, we prepared indocyanine green (ICG) 2 for infusion by adding the dye to a $0.6 \mathrm{~g}$ per $100 \mathrm{ml}$ solution of human serum albumin 3 in normal saline. Such a mixture was shown to be stable for at least 1 week. After a priming dose of $20 \mathrm{mg}$ ICG, the dye was infused intravenously at a constant rate (Sigmamotor pump) of approximately $0.015 \mathrm{mg}$ per minute per $\mathrm{kg}$ of body weight. After a 30-minute period of equilibration, alternating arterial and hepatic venous blood samples were obtained at 5-minute intervals.

Estimation of splanchnic blood volume (SBV). SBV was measured by the regional dilution technique (7). After preliminary blockade of the thyroid gland with 500 $\mathrm{mg}$ of potassium iodide, 15 to $20 \mu \mathrm{c}$ of ${ }^{131}$ I-labeled human serum albumin (RISA) was injected intravenously. Immediately thereafter continuous aspiration of arterial

1 Deseret Intracath no. 17, C. R. Bard, Inc., Murray Hill, N. J.

2 Hynson, Westcott and Dunning, Baltimore, Md.

3 Cutter Laboratories, Berkeley, Calif. 
and hepatic blood was performed at the rate of $1 \mathrm{ml}$ per 10 seconds for a total period of 200 seconds. Initially after 80 seconds, and subsequently at 30 -second intervals, the contents of the aspirating syringes were rapidly emptied through a three-way stopcock into separate centrifuge tubes. To compensate for catheter delay, we did arterial sampling through an identical cardiac catheter.

Determination of BSP transport maximum $(T m)$ and storage capacity $(S)$. BSP was infused intravenously at differing but constant rates during two successive periods. Approximately 0.3 to $0.5 \mathrm{mg} \mathrm{BSP}$ per $\mathrm{kg}$ body weight in $0.9 \%$ saline was administered during the first phase, with progressive elevation in the plasma level. After a period of 30 minutes to permit equilibration and the establishment of a constant rate of change in the BSP plasma level, four arterial blood samples were obtained at accurately timed 5-minute intervals. During the second phase, four blood samples were collected similarly after 30 minutes of equilibration; the amount of BSP infused was now approximately 30 to $40 \%$ of the initial rate, resulting in a steadily falling plasma concentration.

Determination of plasma volume $(P V)$. In all patients, plasma volume was determined with RISA. The radioactivity of a plasma sample, taken 10 minutes after intravenous injection of the tracer, was compared with that of a sample of the injected material diluted to a known volume (with addition of sufficient plasma to prevent adsorption to glass).

Measurement of wedged hepatic venous pressure $(W H V P)$. With the catheter advanced deeply into a right hepatic vein, WHVP was measured with a Statham gauge and a Sanborn recording apparatus (zero reference plane at the right atrium).

Hepatic photoscans. Frontal and lateral hepatic photoscans were obtained in seven patients and in six normal volunteers with a Magnascan 4 apparatus after intravenous injection of $1 \mu \mathrm{c}$ of radioactive gold $\left({ }^{108} \mathrm{Au}\right)$ per pound of body weight.

Sequence of studies. Whenever hemodynamic studies were carried out, determination of BSP $\mathrm{Tm}$ and $\mathrm{S}$ was performed 24 to 48 hours earlier. In the seven patients who underwent hepatic venous catheterization, the studies were made in the following sequence: estimation of $\mathrm{EHBF}$, determination of SBV, measurement of WHVP, and estimation of PV. At each step, immediately before the injection of a tracer, a blood sample was obtained to permit correction for blank radioactivity. The total amount of blood withdrawn for hemodynamic studies did not exceed $125 \mathrm{ml}$.

\section{Analytical methods}

BSP concentrations in plasma were measured in an automated spectrophotometer ${ }^{5}$ at $580 \mathrm{~m} \mu$ after appropriate dilution with an isotonic phosphate buffer $(\mathrm{pH} 6.9$; $250 \mathrm{mOsm}$ per L) and alkalinization with $0.2 \mathrm{ml} 20 \%$

\footnotetext{
4 Picker Nuclear Division, Picker X-Ray Corp., White Plains, N. Y.

5 Research Specialties Co., Richmond, Calif.
}

potassium hydroxide. The optical density of a similarly treated "blank," obtained before infusion of BSP, was subtracted. BSP concentrations in the infusions were measured similarly after appropriate aqueous dilution and alkalinization.

Concentrations of ICG in plasma were determined in undiluted samples, maintained at a constant temperature of $25^{\circ} \mathrm{C}$, and read in a Beckman DU spectrophotometer at $810 \mathrm{~m} \mu$. After subtraction of a plasma blank collected before the start of the ICG infusion, the concentration of the dye was read from a standard line, with the known dye dilutions prepared in pooled human serum. Pooled serum was also used for appropriate dilution of the infusion mixture.

Arterial and hepatic venous oxygen content was measured in blood samples by the method of Van Slyke and Neill (11). Serum bilirubin, serum alkaline phosphatase, serum glutamic oxaloacetic transaminase (SGOT), serum glutamic pyruvic transaminase (SGPT), and serum protein electrophoresis were carried out in the routine clinical laboratory by standard methods.

\section{Computations}

Calculation of EHBF was made according to the formula: $\mathrm{EHBF}=(\mathrm{I} \pm \Delta \mathrm{P} \mathrm{PV}) /(\mathrm{a}-\mathrm{hv}) \times 1 /(1-\mathrm{Hct})$ milliliters per minute, where $I=$ infusion rate for $I C G$ in milligrams per minute; $\Delta \mathrm{P}=$ rate of change of arterial plasma concentration of ICG in milligrams per milliliter per minute; $\mathrm{PV}=$ plasma volume in milliliters ; and $\mathrm{a}=$ arterial and $\mathrm{hv}=$ hepatic venous plasma concentration of ICG in milligrams per milliliter; and $\mathrm{Hct}=$ hematocrit.

$\mathrm{SBV}$ was computed with the formula $\mathrm{SBV}=[(\overline{\mathrm{A}}-\overline{\mathrm{V}})$ $\left.\times t_{\text {eq }} \times \mathrm{EHBF}\right] / \mathrm{A}_{\text {eq }}$ milliliters $(7)$, where $\overline{\mathrm{A}}=$ mean arterial radioactivity during the equilibration time $\left(t_{\mathrm{eq}}\right)$ in counts per minute per milliliter; $\bar{V}=$ mean hepatic venous radioactivity during $t_{e q}$ in counts per minute per milliliter; $t_{e q}=$ equilibration time in seconds; $\mathrm{EHBF}=$ hepatic blood flow in milliliters per second; and $\mathrm{A}_{\text {eq }}=$ arterial plasma radioactivity at equilibrium in counts per minute per milliliter.

Mean splanchnic circulation time was calculated from the values for SBV and $\mathrm{EHBF}$.

BSP Tm and S were computed by solution of simultaneous equations for the two infusion periods (I, II) on

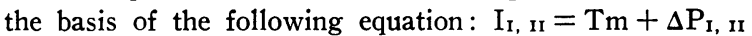

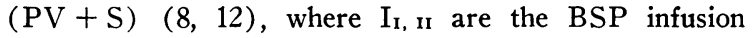
rates (milligrams per minute), $\Delta P_{1}$, II are the changes in plasma BSP concentration (milligrams per $100 \mathrm{ml}$ per minute), and PV is the plasma volume in hundreds of milliliters.

Computation of liver volume was carried out according to the method of Walk (10), with the following modifications : lateral (A), antero-posterior (B), and vertical (C) diameters (Figure 1) were measured on frontal and lateral hepatic photoscans. According to the liver configuration, 3.55 was used as index for the normal, 3.75 for the flat border, and 3.25 for the blunt border, and liver volume was calculated from the formulation: $(\mathrm{A} \times \mathrm{B} \times \mathrm{C}) /$ index units. Thus, it was not possible 

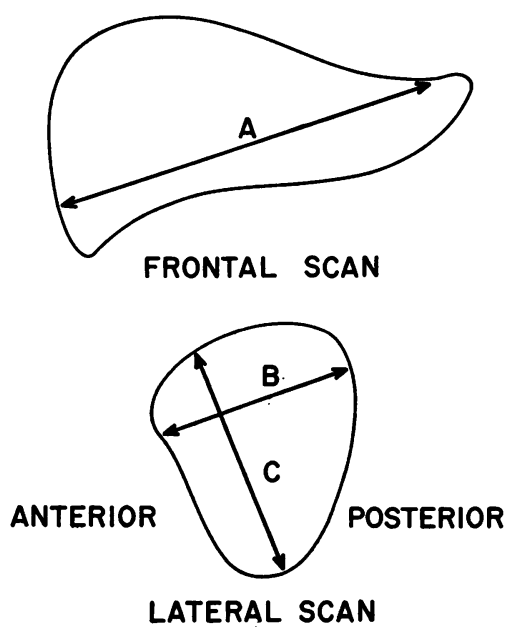

Fig. 1. Schematic Representation of Walk's esSENTIAL DIAMETERS FOR ESTIMATION OF LIVER VOLUME AS APPLIED to hepatic PHotoscans. A, lateral; B, anteroposterior; and $\mathrm{C}$, vertical.

to compare the results to Walk's normal values. Instead, liver volume was determined in six normal volunteers chosen for similar body size (mean surface area $1.96 \mathrm{~m}^{2}$ as compared with $2.05 \mathrm{~m}^{2}$ in the acromegalic patients).

\section{Results}

Clinical pattern. Although selection of patients with unmistakable features of acromegaly, all of whom had received external radiation therapy to the pituitary region, might have been expected to result in a relatively uniform study group, the data summarized in Table I present a pattern of considerable diversity. The ages of the 11 pa- tients ranged from 41 to 66 years, their body weights from 57 to $98 \mathrm{~kg}$, and the "duration" of the illness (dated from confirmation of diagnosis) varied from 2 to 28 years. Overt diabetes mellitus was present in five, but two others (Le. and Ph.) showed diabetic glucose tolerance tests. In the eight in whom serum growth hormone concentration was measured by radioimmunoassay, ${ }^{6}$ no correlation was evident between serum growth hormone level and duration of illness or presence of diabetes mellitus. Although serum protein-bound iodine (PBI) was normal in all, thyroidal abnormalities were present in 5 of the 11 patients at one time or another (as evidenced by a history of subtotal thyroidectomy or the finding of thyroidal enlargement on physical examination). Three patients gave a history of previous subtotal gastrectomy for duodenal ulcer. One of these (Ha.) also had a parathyroid adenoma. No patient was receiving endocrine replacement therapy, except for St. and Fr., who were taking insulin and tolbutamide, respectively.

This variability in the clinical manifestations of acromegaly was in contrast to the relatively uniform changes in size, excretory capacity, and circulatory pattern of the liver.

Liver size. Calculation of liver volume, based on measurements of lateral, posteroanterior, and

${ }^{6}$ We are indebted to Drs. Selna Kaplan and Melvin M. Grumbach of the Dept. of Pediatrics for performing the serum growth hormone determinations.

TABLE I

Clinical data in 11 patients with acromegaly

\begin{tabular}{|c|c|c|c|c|c|c|c|c|c|}
\hline Name & Sex & Age & Weight & $\begin{array}{l}\text { Year of } \\
\text { diag-- } \\
\text { nosis }\end{array}$ & $\begin{array}{c}\text { Radia- } \\
\text { tion to } \\
\text { pitu- } \\
\text { itary }\end{array}$ & $\begin{array}{c}\text { Sellar } \\
\text { enlarge- } \\
\text { ment } \\
\text { (X ray) }\end{array}$ & $\begin{array}{l}\text { Diabetes } \\
\text { mellitus }\end{array}$ & $\underset{\mathrm{GH}^{*}}{\text { Serum }}$ & Remarks \\
\hline & & years & kg & & & & & $m \mu g / m l$ & \\
\hline St. & $\mathbf{M}$ & 55 & 97.7 & 1963 & + & + & + & 3.4 & Thyroid enlarged; liver palpable \\
\hline Le. & $\mathbf{M}$ & 42 & 93.3 & 1947 & + & + & $\underset{\text { GTT } \dagger}{\text { Abnormal }}$ & 10.0 & $\begin{array}{l}\text { Gastrectomy in } 1963 \text {; thyroidectomy } \\
\text { in } 1957\end{array}$ \\
\hline Ha. & $\mathbf{M}$ & 41 & 93.2 & 1959 & + & + & + & 20.0 & $\begin{array}{l}\text { Gastrectomy in } 1962 \text {; parathyroid } \\
\text { adenoma removed in } 1965\end{array}$ \\
\hline Di. & $\mathbf{M}$ & 56 & 91.8 & 1962 & + & + & + & 1.0 & \\
\hline Ro. & $\mathbf{M}$ & 45 & 91.8 & 1961 & + & + & 0 & 140.0 & \\
\hline Ba. & $\mathbf{M}$ & 66 & 84.2 & 1940 & + & 0 & $\mathbf{0}$ & & \\
\hline Pi. & F & 62 & 91.4 & 1959 & + & + & + & & Thyroidectomy in 1927 and 1959 \\
\hline Fr. & $\mathbf{F}$ & 61 & 84.5 & 1937 & + & + & + & 1.9 & \\
\hline - Na. & F & 44 & 84.2 & 1956 & + & + & $\mathbf{0}$ & 50.0 & Thyroidectomy in 1960 \\
\hline Sw. & $\mathrm{F}$ & 54 & 62.0 & 1938 & + & + & $\mathbf{0}$ & & \\
\hline Ph. & $\mathrm{F}$ & 43 & 56.8 & 1954 & + & + & $\begin{array}{c}\text { Abnormal } \\
\text { GTT }\end{array}$ & 7.0 & Thyroid enlarged \\
\hline
\end{tabular}

* $\mathrm{GH}=$ fasting serum growth hormone concentration by radioimmunoassay, normal value $<5 \mathrm{~m} \mu \mathrm{g}$ per $\mathrm{ml}$. $\dagger \mathrm{GTT}=$ glucose tolerance test. 
TABLE II

"Liver vclume" and splanchnic hemodynamics in acromegaly

\begin{tabular}{|c|c|c|c|c|c|c|c|c|c|c|c|}
\hline \multirow[b]{2}{*}{ Name } & \multirow[b]{2}{*}{$\begin{array}{l}\text { Liver } \\
\text { volume }\end{array}$} & \multicolumn{2}{|c|}{ Indocyanine green } & \multirow[b]{2}{*}{$\begin{array}{l}\text { Estimated } \\
\text { hepatic } \\
\text { blood flow }\end{array}$} & \multirow[b]{2}{*}{$\begin{array}{c}\text { Wedged } \\
\text { hepatic } \\
\text { venous } \\
\text { pressure }\end{array}$} & \multirow[b]{2}{*}{$\begin{array}{l}\text { Arteriohepatic } \\
\text { venous oxygen } \\
\text { difference }\end{array}$} & \multirow[b]{2}{*}{$\begin{array}{l}\text { Splanchnic } \\
\text { mean circu- } \\
\text { lation time }\end{array}$} & \multirow[b]{2}{*}{$\begin{array}{c}\text { Splanchnic } \\
\text { blood } \\
\text { volume }\end{array}$} & \multirow[b]{2}{*}{$\begin{array}{c}\text { Total } \\
\text { blood } \\
\text { volume }\end{array}$} & \multirow[b]{2}{*}{$\begin{array}{c}\text { Splanchnic } \\
\text { total blood } \\
\text { volume } \times 100\end{array}$} & \multirow[b]{2}{*}{ Hema- } \\
\hline & & $\begin{array}{l}\text { Plasma } \\
\text { concen- } \\
\text { tration }\end{array}$ & $\begin{array}{l}\text { Hepatic } \\
\text { extraction } \\
\text { ratio }\end{array}$ & & & & & & & & \\
\hline & $U$ & $\mathrm{mg} / 100 \mathrm{ml}$ & al $\%$ & $m l / m i n$ & $\mathrm{~mm} / \mathrm{Hg}$ & $v o l / 100 \mathrm{ml}$ & $\sec$ & $m l$ & $m l$ & $\%$ & $\%$ \\
\hline St. & 2,120 & 0.21 & 54 & 1,710 & 7 & & 32.7 & 870 & 5,470 & 15.9 & 39 \\
\hline Le. & 1,480 & 0.08 & 82 & 1,770 & & 4.7 & 45.9 & 1,360 & 6,550 & 20.8 & 37 \\
\hline $\mathrm{Ha}$. & 1,590 & 0.14 & 91 & 1,700 & 9 & 5.3 & 33.4 & 940 & 6,860 & 13.7 & 37 \\
\hline Di. & 1,240 & 0.14 & 80 & 1,590 & 9 & 3.5 & 33.8 & 900 & 6,030 & 14.9 & 41 \\
\hline $\mathrm{Ba}$. & 1,870 & 0.14 & 87 & 1,640 & 7 & 5.7 & 36.6 & 1,000 & 5,890 & 17.0 & 40 \\
\hline $\mathrm{Na}$. & 1,930 & 0.10 & 72 & 2,080 & 6 & 4.4 & 34.6 & 1,100 & 4,890 & 22.5 & 36 \\
\hline $\mathrm{Ph}$. & 1,010 & 0.15 & 84 & 1,100 & & & & & 4.070 & $\cdot$ & 35 \\
\hline Mean & 1,610 & & 79 & 1,660 & 8 & 4.7 & 36.2 & 1,030 & & 17.5 & \\
\hline $\begin{array}{l}\text { Mean } \\
\text { normal } \\
\text { value }\end{array}$ & $1,050(6)^{*}$ & & $63(4)$ & $1,530(91)$ & 8 & $3.8(27)$ & $39.9(5)$ & 1,020 & & $19.1(10)$ & \\
\hline SD & 150 & & & 300 & & 0.71 & 5.8 & 300 & & 3.8 & \\
\hline $\begin{array}{l}\text { References } \\
\text { for normal } \\
\text { values }\end{array}$ & (See text) & & (13) & (14) & (15) & (14) & (16) & (15) & & (15) & \\
\hline
\end{tabular}

* Numbers in parentheses on this line represent number of subjects on which the normal mean is based.
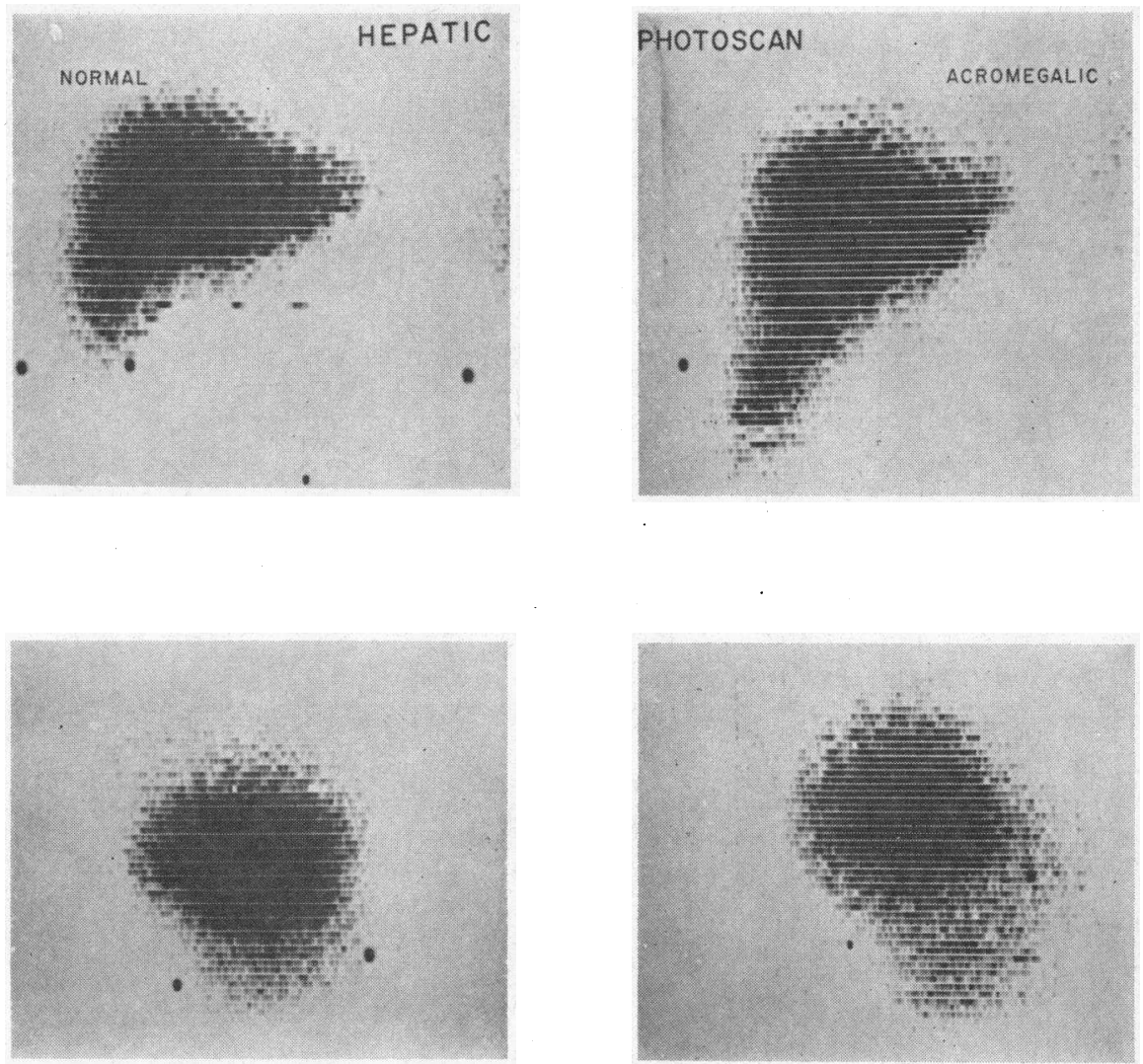

Fig. 2. Representative frontal and lateral hepatic photoscans obtained from NORMal AND ACROMEgalic sUbjects. Predominant enlargement in the "vertical" axis (see Figure 1) is evident in the lateral scan of the acromegalic. 
vertical diameter of hepatic photoscans (Figure 1) and corrected for hepatic configuration with the factors derived from Walk's studies (10), yielded an average value of $1,610 \mathrm{U}$ in the seven patients, as compared with a mean of $1,050 \mathrm{U}$ in six volunteers of similar size (Table II). With two exceptions ( $\mathrm{Di}$. and $\mathrm{Ph}$. ), all values were in excess of $1,350 \mathrm{U}$ (normal mean plus $2 \mathrm{SD}$ ). Thus, liver size was increased roughly one and one-half times above normal (Figure 2), a relationship that remains essentially unchanged when the values are corrected for body surface area ("relative liver volume"). In only one of the patients so studied (St.) was the liver enlarged to palpation. This tendency of the liver to enlarge in what Walk refers to as the "vertical" axis-thus escaping clinical detection as hepatomegaly-is evident in Figure 2 , in which typical hepatic photoscans from an acromegalic subject are compared with those of a normal volunteer of similar body size. No abnormal extrahepatic uptake of ${ }^{198} \mathrm{Au}$ was observed.

Splanchnic hemodynamics. Hepatic blood flow was measured in seven patients (Table II). The values obtained ranged from 1,100 to $2,080 \mathrm{ml}$ per minute, with a mean of $1,660 \mathrm{ml}$ per minute, which is well within normal limits (normal : $1,530 \pm 300$ ml per minute, BSP method) (14). The hepatic extraction for ICG varied from 54 to $91 \%$, averaging $79 \%$ in the entire group. With the exception of St., the values were above $63 \%$, the reported normal mean value for comparable plasma levels of ICG (13). Since the values for blood flow were within normal limits, and since plasma concentrations were never excessively high (Table II), the observed increase in ICG extraction must be due to increased uptake by the liver (whether because of increased hepatic functional mass or enhanced uptake), to decreased velocity of blood flow, or to both.

In keeping with this interpretation are the results of hepatic arteriovenous oxygen differences (a-hv $\mathrm{O}_{2}$ ), studied on five occasions. The values ranged from 4.4 to 5.7 vol per $100 \mathrm{ml}$ and were on the average increased by $25 \%$ (normal: $3.8 \pm$ SD 0.71 vol per $100 \mathrm{ml}$ ) (14). When computed in terms of total splanchnic oxygen uptake, this increase became even more prominent $(83,90,56$, 94, and 92 vol per minute in Le., Ha., Di., Ba.. and Na., respectively, compared with the normal of $67 \pm$ SD 17 vol per minute) (14).
SBV was measured in six patients; the values of 870 to $1,360 \mathrm{ml}$ (or from 14 to $23 \%$ of the total blood volume) clustered closely about the normal mean of $1,030 \pm \mathrm{SD} 300 \mathrm{ml}$ (or $19.1 \pm \mathrm{SD} 3.8 \%$, respectively) (15). In general, the values for SBV were well correlated with the splanchnic mean circulation time, which ranged from 32.7 to 45.9 seconds (Table II).

WHVP, determined in five subjects, was within normal limits (Table II), as were arterial blood pressure and total blood volume in all patients.

Routine liver function tests. All the biochemical tests, including serum bilirubin (range 0.2 to 0.7 $\mathrm{mg}$ per $100 \mathrm{ml}$, normal mean $0.5 \pm \mathrm{SD} 0.3$ ), serum alkaline phosphatase (range 2 to 12 KingArmstrong units, normal mean $6 \pm$ SD 2), SGOT, SGPT, and serum electrophoresis, gave normal results.

BSP storage capacity and transport maximum. BSP S ranged from 37 to $78 \mathrm{mg}$ per $\mathrm{mg}$ per 100 $\mathrm{ml}$ (mean 51, normal value $51 \pm \mathrm{SD} 12$ ) in the women, and from 47 to $127 \mathrm{mg}$ per $\mathrm{mg}$ per 100 $\mathrm{ml}$ (mean 74, normal value $69 \pm \mathrm{SD} \mathrm{17}$ ) in the men (Figure 3 ). These values were within normal limits in both groups (12). Only in Ha. was the value for $\mathrm{S}$ slightly above the normal range, as defined by the normal mean plus $2 \mathrm{SD}$. Thus, it is evident that $\mathrm{S}$ does not parallel the increase in liver size in acromegalic patients.

By contrast, Tm, like liver volume, was markedly augmented in each patient and was on the average doubled in both sexes. The mean value was $17.6 \mathrm{mg}$ per minute (normal 9.6 \pm SD 1.9)

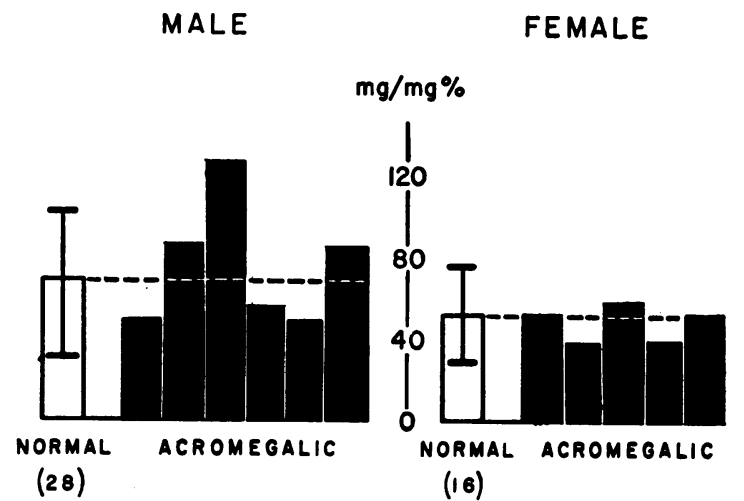

Fig. 3. Sulfobromophthalein (BSP) relative STORAGE CAPACITY IN MALE AND FEMALE ACROMEgaliC patients (solid BARs). Mean normal values ( \pm 2 SD) are depicted by the open bars (12). 
MALE

FEMALE

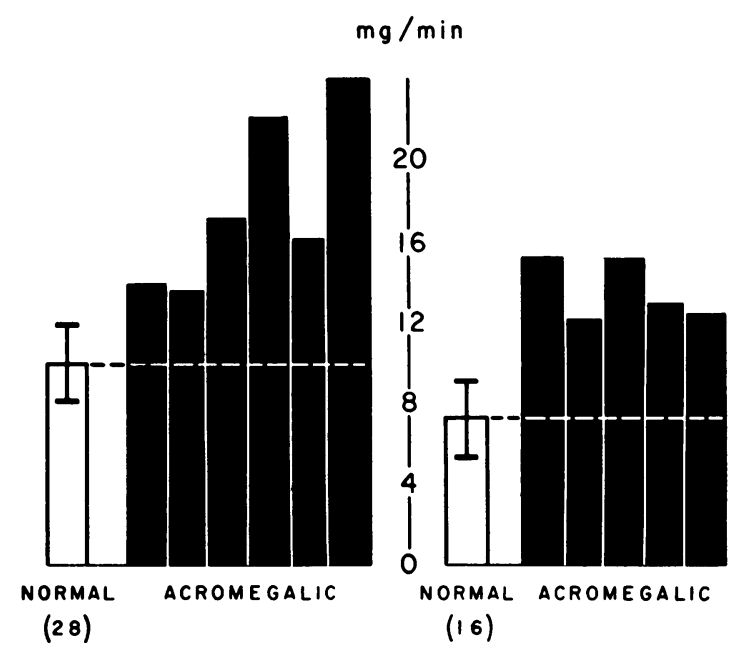

Fig. 4. BSP tRanSPort MAXIMUM in Male AND FEmale aCromegailic SUbjects (solid bars). Mean normal values $( \pm 2 \mathrm{SD})$ are shown by the open bars (12).

for the males, $13.5 \mathrm{mg}$ per minute (normal $7.2 \pm$ SD 1.9) for the females, ranging from 13.3 to 23.9 and 12.0 to $15.1 \mathrm{mg}$ per minute in the two groups, respectively (Figure 4). Within the groups of men and women there was no evidence of correlation between BSP Tm and body size, nor did liver volume (seven patients) correlate with $\mathrm{Tm}$, except in a general way. The women, however, were on the average smaller than the men, and both $\mathrm{S}$ and $\mathrm{Tm}$ differed significantly between the two sexes. This observation is in keeping with the results obtained in normal subjects (12). One cannot be certain whether the difference is related to sex or to body size.

\section{Discussion}

The studies reported in this paper provide evidence that the acromegalic liver is characterized by an increase in size, a distinct circulatory pattern, and a uniform functional change in the face of a marked diversity of clinical findings. The mechanisms that produce these changes are obscure. Excessive secretion of pituitary growth hormone is generally considered to be the major factor in the pathogenesis of acromegaly, although precise correlation of serum growth hormone value with clinical "activity" of the clisease is by no means established. Furthermore, it is not known that the increase in circulating growth hormone is directly or solely responsible for the visceral enlargement. Whereas autopsy studies attest convincingly to the presence of hepatic enlargement, discovery of hepatomegaly on clinical examination may be rather difficult. This was certainly true in the present series of patients. The liver was enlarged by palpation in only one, whereas unequivocal evidence for hepatomegaly was obtained in five of seven patients studied with photoscanning. With the aid of this technique, it was also possible to quantify the hepatic enlargement. Comparison of the calculated values for liver volume with those obtained in normal volunteers disclosed a substantial increase in hepatic size (one and one-half times, on the average). In the absence of pretreatment photoscans, it is not possible to assess the precise relation between liver size and radiation treatment to the pituitary. One can state, however, that hepatomegaly is observed after such treatment.

The structural changes responsible for hepatic enlargement are not well defined. Pathologists who have studied visceromegaly in acromegalic subjects have not been able to decide whether hypertrophy of individual cells, hyperplasia, or both are responsible (17). In addition, intercellular edema has been implicated as a result of examination of tissue obtained from experimental animals treated with growth hormone (18). Information on rate of growth of vascular, parenchymal, and connective tissue components is altogether lacking.

From a correlative study of renal structure and function in a single acromegalic patient, Gershberg, Heinemann, and Stumpf were able to demonstrate that glomerular and proximal tubular functions were increased, although not in proportion to organ weight; changes in the function of the distal tubules, however, were not detectable (5). In view of these disparate findings for individual renal functions one might anticipate that the enlarged acromegalic liver is characterized by changes that differ in their effects upon parenchymal, biliary (or excretory), and circulatory functions. This hypothesis was confirmed by measurement of BSP S, an index of the functional hepatocellular mass, and of BSP $\mathrm{Tm}$, an index of biliary function. Whereas storage capacity was well within normal limits, mean transfer maximum was increased twofold. This pattern was quite uniform in spite of the considerable variation 
in liver size. The lack of correlation between liver volume and BSP S suggests that the increment in hepatic mass is not primarily due to hyperplasia of "normal" parenchymal tissue. Such an assumption would also imply that, in the strict classical sense, hypertrophy rather than hyperplasia of hepatocytes is present and that this results in a marked augmentation of their excretory capacity, since for the data as a whole BSP Tm was increased roughly in proportion to liver size. Alternatively, one might assume that the parenchymal increment is made up predominately of "excretory cells." Although there is no evidence for heterogeneity among hepatocytes in terms of "storage" and "biliary transfer" of dyes or other materials, a complete dissociation of hepatocellular and excretory function is known to exist in patients with, for example, Dubin-Johnson syndrome (9). In the absence of hepatic enlargement, uptake of BSP is normal in that disorder, but biliary excretion is virtually nonexistent. It seems reasonable, therefore, to consider the possibility that in acromegaly the selective increase in biliary BSP excretion is not primarily related to changes in liver size, but rather is due to alterations in enzymatic processes within the hepatocytes. In keeping with such a hypothesis is the fact that BSP is largely conjugated in the liver with glutathione (19), a process catalyzed presumably by a specific enzyme (20). Although it is established that conjugation is not essential to biliary excretion, the possibility cannot be excluded that conjugation in some way facilitates biliary transfer of the dye (21). Hence, an increase in the maximal excretory rate might be due to augmented enzymatic activity. Clearly, further studies of biliary transfer of materials such as rose bengal or indocyanine green, which are not altered by the liver cell, may help to elucidate this point.

A question should also be raised concerning the interpretation of the abnormal values for BSP Tm. Although the method of determination is based upon the postulate that the equation $\mathrm{I}=\mathrm{Tm}+$ $\Delta \mathrm{P}(\mathrm{PV}+\mathrm{S})$ describes all factors determining kinetics of the infused dye, it is well known that small amounts of BSP escape into urine and extracellular fluid. Normally, these losses are so small that they can be disregarded. Although urinary BSP output was less than $1 \%$ of the in- fused amount in patients reported here, movement into the extracellular fluid compartment, which is known to be expanded in acromegalics (3), could not be quantified. If such escape of dye had been markedly increased, however, it should have resulted in falsely high values for both $\mathrm{S}$ and Tm. It seems reasonable to conclude, therefore, that the pattern of $\mathrm{S}$ and $\mathrm{Tm}$ can be ascribed to the hepatic changes alone.

Characterization of the hepatic hemodynamics did not provide an explanation for this "excretory gigantism." Uniformly normal values for hepatic blood flows and splanchnic blood volumes were observed, in spite of the considerable variability among patients and in contrast to the findings of increased renal blood flow in acromegaly (3-5). Maintenance of a normal hepatic circulatory pattern implies, however, a relative reduction in tissue perfusion, which is proportional to the increment in hepatic mass. Such an interpretation is further substantiated by the mean increase of approximately $25 \%$ in a-hv $\mathrm{O}_{2}$. The increment observed in the extraction of ICG may similarly reflect changes in perfusion as well as alterations in cellular function. Whether the apparent relationship between increases in liver volume and splanchnic oxygen consumption (computed as the product of $\mathrm{EHBF}$ and a-hv $\mathrm{O}_{2}$ ) implies that the hepatomegaly is to a large extent due to expansion of the oxygen-consuming cell mass, or whether the perfused tissue consumes oxygen at a rate greater than normal cannot be stated. It should be pointed out that a-hv $\mathrm{O}_{2}$ reflects uptake of oxygen by extrahepatic splanchnic viscera as well as the liver, so that the increase in oxygen consumption may be at least in part due to augmented extrahepatic uptake.

Of particular interest is the fact that hypertrophy of cellular constituents, if this occurs, does not appear to encroach upon intrahepatic vascular pathways. Since wedged hepatic venous pressure was normal, resistance to at least hepatic venous outflow was unaffected. Although there was no evidence of portal hypertension in these patients, any effects of changes in portal venular resistance upon EHBF might be so small that they could easily remain undetected with the present methods employed for measurement of hepatic blood flow (15). Nevertheless, the finding of a normal splanchnic blood volume suggests that the 
splanchnomegaly is associated with a relative reduction in the volume of actively circulating blood in the splanchnic bed.

Clearly, further work is needed to define the development of these functional alterations. Finally, definition of the excretory fate of natural substances, such as bilirubin, bile acids, and other steroid compounds normally handled by mechanisms similar to those involved in BSP excretion may further elucidate the function of the liver in acromegaly, and studies of this kind may provide further insight into the role of the liver in homeostasis.

\section{Summary}

Hepatic parenchymal and biliary functions were assessed in 11 patients with clinical features of acromegaly by determination of storage capacity (S) and transfer maximum ( $\mathrm{Tm}$ ) for sulfobromophthalein (BSP). In spite of considerable clinical diversity, BSP Tm was increased in every patient, averaging $17.6 \mathrm{mg}$ per minute (normal $9.6 \pm \mathrm{SD} 1.9)$ in the $6 \mathrm{men}$, and $13.5 \mathrm{mg}$ per minute (normal $7.2 \pm \mathrm{SD} 1.9$ ) in the 5 women. BSP $\mathrm{S}$ was within normal limits. Although "liver volume," calculated from measurements of hepatic photoscans, was augmented by approximately $50 \%$ in 5 of 7 patients, splanchnic blood flow (EHBF, dye dilution and extraction technique) and volume (regional dilution technique) remained entirely normal. This, together with increased hepatic extraction for indocyanine green (mean $79 \%$, as compared with the normal of $63 \%$ ) and oxygen, suggests a relative reduction in tissue perfusion that is proportional to the increment in hepatic mass.

The mechanisms responsible for the augmented excretory capacity for BSP remain obscure. Changes in enzymatic processes within parenchymal cells are considered a possible explanation.

\section{Acknowledgments}

Hiroko Otani, Annegreth Taylor, and Eleanor Bachthaler provided skillful technical assistance, and Rosemarie Arnold, R.N., and Linda Green, R.N., gave indispensable help in the care of the patients. Drs. Ernest Schwartz of the Bronx Veterans Administration Hospital and Jack Geller of the Albert Einstein College of Medicine kindly referred patients to us for study; Dr. Solomon A. Berson carried out determinations for serum growth hormone concentration in some of these subjects.
We are particularly grateful to Dr. Stanley E. Bradley, in whose laboratory these studies were made, for his constant encouragement and critical advice throughout the course of this investigation.

\section{References}

1. Gordon, D. A., F. M. Hill, and C. Ezrin. Acromegaly: a review of 100 cases. Canad. med. Ass. J. 1962, 87, 1106.

2. Coggeshall, C., and H. F. Root. Acromegaly and diabetes mellitus. Endocrinology 1940, 26, 1.

3. Falkheden, T., and B. Sjögren. Extracellular fluid volume and renal function in pituitary insufficiency and acromegaly. Acta endocr. (Kbh.) 1964, 46, 80.

4. Ikkos, D., H. Ljunggren, and R. Luft. Glomerular filtration rates and renal plasma flow in acromegaly. Acta endocr. (Kbh.) 1956, 21, 226.

5. Gershberg, H., H. O. Heinemann, and H. H. Stumpf. Renal function studies and autopsy report in a patient with gigantism and acromegaly. J. clin. Endocr. 1957, 17, 377.

6. Bradley, S. E., F. J. Ingelfinger, G. P. Bradley, and J. J. Curry. The estimation of hepatic blood flow in man. J. clin. Invest. 1945, 24, 890.

7. Bradley, S. E., P. A. Marks, P. C. Reynell, and J. Meltzer. The circulating splanchnic blood volume in dog and man. Trans. Ass. Amer. Phycns 1953, 66, 294.

8. Bradley, S. E. The excretory function of the liver. Harvey Lect. 1958-1959, 54, 131.

9. Wheeler, H. O., J. I. Meltzer, and S. E. Bradley. Biliary transport and hepatic storage of sulfobromophthalein sodium in the unanesthetized dog. in normal man, and in patients with hepatic disease. J. clin. Invest. 1960, 39, 1131.

10. Walk, L. Roentgenologic determination of the liver volume. Acta Radiol. (Stockh.) 1961, 55, 49.

11. Van Slyke, D. D., and J. M. Neill. The determination of gases in blood and other solutions by vacuum extraction and manometric measurement. $\mathrm{J}$. biol. Chem. 1924, 61, 523.

12. Preisig, R., R. Williams, J. Sweeting, and S. E. Bradley. Changes in sulfobromophthalein transport and storage by the liver during viral hepatitis in man. Amer. J. Med. 1966, 40, 170.

13. Caesar, J., S. Shaldon, L. Chiandussi, L. Guevara, and S. Sherlock. The use of indocyanine green in the measurement of hepatic blood flow and as a test of hepatic function. Clin. Sci. 1961, 21, 43.

14. Bradley, S. E., F. J. Ingelfinger, and G. P. Bradley. Hepatic circulation in cirrhosis of the liver. Circulation 1952, 5, 419.

15. Bradley, S. E. Circulation, Section 2 in Handbook of Physiology, vol. 2, W. F. Hamilton, Ed. Washington, D. C., American Physiological Society, 1963, 1387.

16. Wade, O. L., B. Combes, A. W. Childs, H. O. Wheeler, A. Cournand, and S. E. Bradley. The effect of exercise on the splanchnic blood flow and 
splanchnic blood volume in normal man. Clin. Sci. 1956, 15, 457.

17. Cushing, H., and L. Davidoff. The pathological findings in four autopsied cases of acromegaly, with a discussion of their significance. Monograph 22 of the Rockefeller Institute of Medical Research, New York, 1927.

18. Putnam, T. J., E. B. Benedict, and H. M. Teel. Studies in acromegaly. VIII. Experimental canine acromegaly produced by injection of anterior lobe pituitary extract. Arch. Surg. 1929, 18, 1708.
19. Javitt, N. B., H. O. Wheeler, K. J. Baker, O. L. Ramos, and S. E. Bradley. The intrahepatic conjugation of sulfobromophthalein and glutathione in the dog. J. clin. Invest. 1960, 39, 1570.

20. Combes, B., and G. S. Stakelum. A liver enzyme that conjugates sulfobromophthalein sodium with glutathione. J. clin. Invest. 1961, 40, 981.

21. Combes, B. The importance of conjugation with glutathione for sulfobromophthalein sodium (BSP) transfer from blood to bile. J. clin. Invest. 1965, 44, 1214. 